\title{
The trachea in children with respiratory diseases including children presenting as cot deaths
}

\author{
M WAILOO AND J L EMERY \\ Department of Pathology, Children's Hospital, Sheffield
}

SUMMARY The tracheas of 74 children with respiratory disorders were analysed and compared with the tracheas of children with no respiratory symptoms. The test tracheas showed an increase in the size of the lumen and the length of the cartilage and membrane, the increase in the length of membrane being particularly striking. The relation between age at onset and duration of symptoms was uncertain.

There has been an increased awareness of respiratory disease in children associated with abnormally collapsible tracheas. ${ }^{1-3}$ The identification of these deformities requires a high level of suspicion on the part of the clinician and also, usually, specially skilled radiology and endoscopy. In the absence of clinical suspicion or diagnosis, detection at necropsy can be easily overlooked when the abnormality is not gross, or in children who present as unexpected deaths in whom the histories are often incomplete. For these reasons, we thought it useful to survey the tracheas of children who had respiratory symptoms and in whom no diagnosis of tracheal anomaly had been made for evidence of missed or hidden abnormalities.

\section{Materials and methods}

Tracheas taken from 1000 sequential necropsies of children of all ages were analysed for structural abnormalities. At necropsy, the main bronchi had been opened and the whole trachea fixed in $10 \%$ formol calcium for 4 days. A standard transverse, midtracheal block was removed, sectioned, and stained with Goldner's trichrome. The section was projected at a standardised magnification on to a flat surface and, with the aid of a map measure, the following measurements were made: (1) length of the transverse muscle-that is, the length of the membranous trachea; (2) length of internal perimeter, at the level of the basement membrane; (3) length of the tracheal cartilage.

The ratio of the length of cartilage to length of

Congenital Anomalies Research Unit, Children's Hospital, Sheffield

J L EMERY, professor of paediatric pathology

University of Southampton

$M$ WAILOO, lecturer in paediatrics muscle was calculated from (1) and (2), and this was used as an index of tracheal wall shape. All measurements were made at a time when the clinical history and the ages of the children were not known. Later, from the case histories, the crown to rump lengths, ages, and relevant history were obtained and correlated with the tracheal measurements.

From the history and necropsy findings, the children were divided into three groups: (1) children with any congenital deformity affecting any system, whether or not there were abnormalities or symptoms related to the respiratory tract (339 cases); (2) children with no developmental deformity, with no history of respiratory symptoms, or recognised disease of the respiratory tract on histology. These constituted our 'normal' group (392 cases); (3) children with no gross deformity of any system but with respiratory symptoms, with or without histopathological evidence of respiratory diseases (74 cases).

Only children of groups $\mathbf{2}$ and $\mathbf{3}$ are considered in the present study. The 392 'normal' tracheas (group 2) were used to calculate normal structure, size, and pattern of growth of the trachea.

Of the 74 who had respiratory tract diseases at various times (group 3), 47 presented as sudden unexpected death in infancy-that is, cot deaths. These 74 children were classified according to 'age at onset' as follows: 0-4 weeks (17); 5-8 weeks (11); 9-12 weeks (14); 4-6 months (11); 7-12 months (8); 1 year plus (13). 42 had had symptoms for less than 28 days and 32 for at least one month.

\section{Results}

The measurements of the internal perimeter, 
cartilage, and muscle, and the ratios of cartilage/ muscle related to crown to rump length for the 74 children are shown in Figs 1-4 against measurements derived from the group of 392 'normal' children (group 2).

Of the measurements of the internal perimeter shown in Fig. 1, 38 are above the mean, with 3 higher than the 95th centile; there are 17 below the mean line, with 2 below the 5 th centile. There are many tracheas that are wider than those of the controls $(0.001<\mathrm{P}>0.01)$.

In the analysis of the length of tracheal cartilage, a similar pattern of distribution is obtained (Fig. 2).

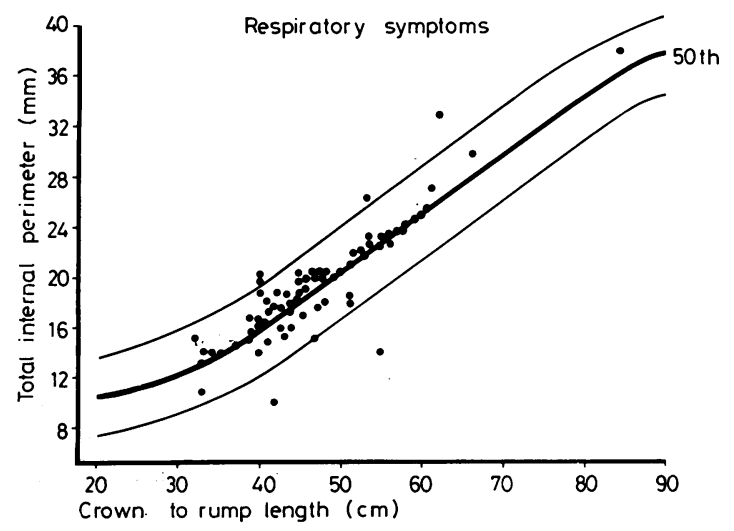

Fig. 1 Measurements of the internal perimeter of the 74 tracheas are distributed around the mean. There are many tracheas which are larger than normal $(0.001<P>0.01)$.

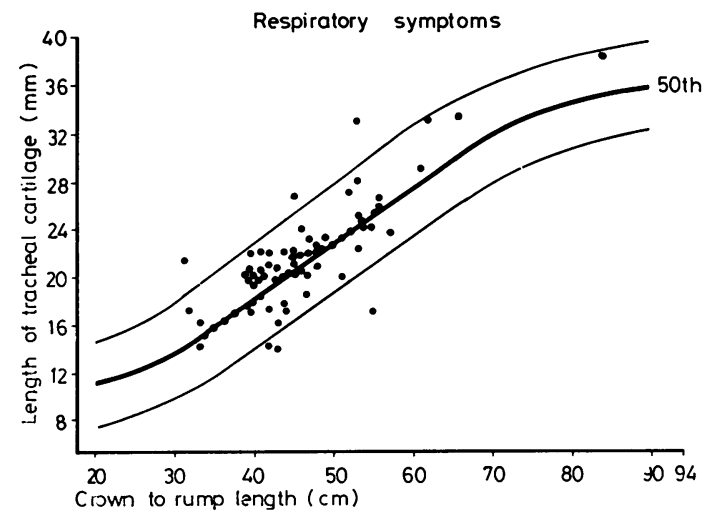

Fig. 2 Lengths of the cartilage of the 74 test tracheas are shown distributed about the mean. Many measurements are above the mean.
37 of the readings are above the mean line, 3 being above the 95th centile; there are 17 below the mean line, with 3 below the 5 th centile. There is an increased proportion of tracheas with longer than normal cartilage.

With the membranous trachea (Fig. 3), 44 measurement readings are larger than the mean, 3 being above the 95th centile, and 18 below the mean line. The significance of this distribution $(P>0.001)$ is greater than that of the internal perimeter and cartilage. The greater the proportion of the wall that is cartilage, the more rigid and less collapsible the trachea. When the ratio of cartilage to muscle is charted (Fig. 4), there are 43 readings below and 17 above the mean suggesting that, in many cases, the ratio is reduced $(P>0 \cdot 001)$. As there is an increase in both cartilage and muscle, the reduced ratio suggests that the relative increase in the length of the membranous trachea is greater than that of the cartilage.

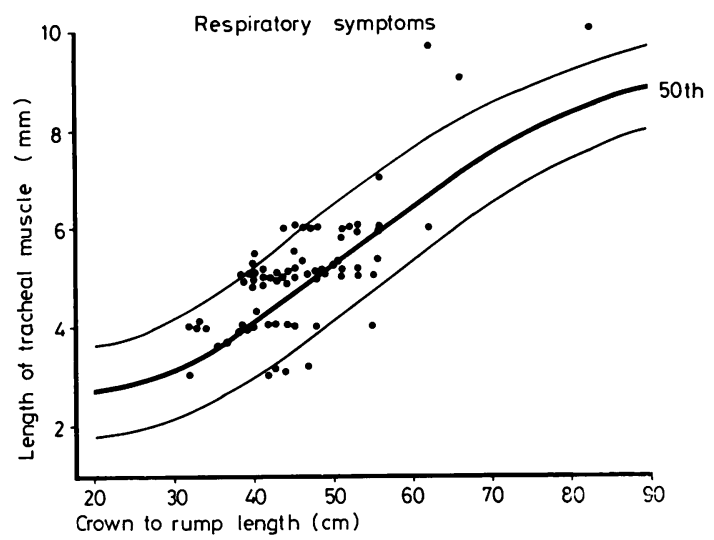

Fig. 374 measurements of the tracheal membrane from children with symptoms referrable to the respiratory tract. Many are longer than the mean.

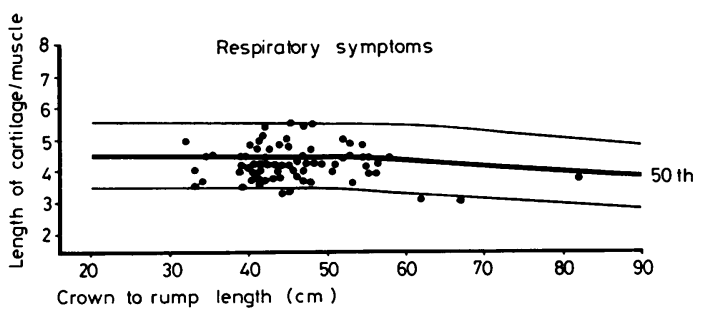

Fig. 4 Ratio of length of cartilage to length of muscle is shown against the normal. In the 74 test tracheas, this ratio is lower than normal, as shown by the distribution of the readings. This suggests that the increase in length of the membranous trachea is greater than that of the cartilage. 
To estimate the relation between the duration of coughing and wheezing and the length of muscle, we have related the length of muscle to age at onset and duration of symptoms; the results are shown in Figs 5 and 6. Generally, children who started coughing and wheezing at an early age, and those in whom symptoms were more prolonged, appear to have the greatest increase in the length of muscle. We have insufficient numbers however, to determine if the differences are statistically significant.

The following three case histories are examples of cases used in the study:

\section{Case histories}

Case 1 (aged $5 \frac{1}{2}$ years). This child had been well until age one year when, after an episode of respiratory tract infection with cough, she developed a series of occurrences of acute dyspnoea with wheezing. A diagnosis of 'asthma' was made at age 2 years, and she received treatment in the form of bronchodilators initially and corticosteroids subsequently for her severe attacks. Later, her corticosteroid administration was unsupervised, drugs being given at her parents' discretion. Her final illness started with a
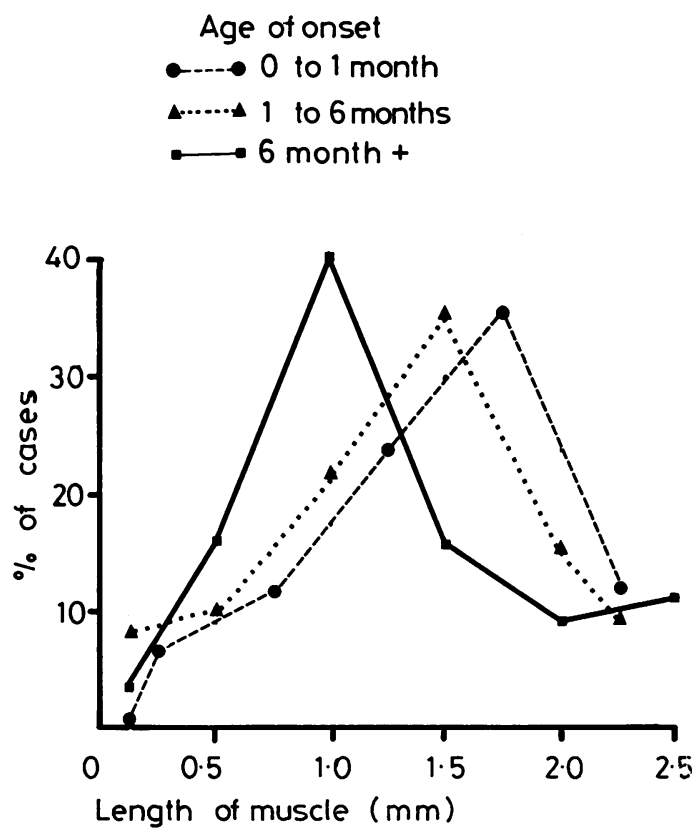

Fig. 5 When the length of tracheal muscle is related to age of onset of respiratory symptoms, children who have the earliest onset of symptoms tend to have longer tracheal muscles than those with a later onset of symptoms.

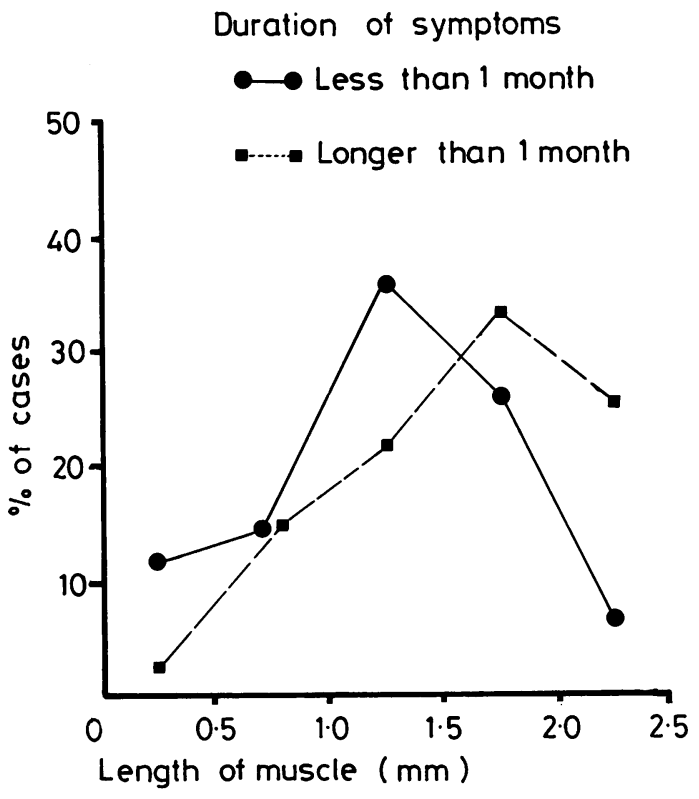

Fig. 6 When the length of tracheal muscle is related to duration of symptoms, those with the longer duration have longer tracheal membranes; the difference, however, is not statistically significant.

sore throat, coughing, shortness of breath, and vomiting related to her coughing. After 4 days, she was admitted to hospital in extremis with severe bilateral bronchopneumonia for which she received antibiotics and controlled oxygen treatment. Her condition deteriorated and she died despite active resuscitation.

\section{Necropsy findings}

The naked-eye necropsy showed evidence of patchy consolidation and pneumonia with purulent fluid in trachea. Histologically, the trachea showed thickening of the basement membrane with dense round cell infiltration. The tracheal muscle measured $9.3 \mathrm{~mm}$ which was above the 100 th centile for her crown to rump length.

Case 2 (aged 4 months). The third child of the family, the result of a normal pregnancy and delivery. Birthweight was $4 \cdot 2 \mathrm{~kg}$. His breathing had always been abnormal and was associated with a hacking cough rather like that of an old man. The cough was worse during the day and almost invariably made him vomit. No congenital deformities, in particular of the heart, could be detected; there was no family 
history of respiratory illness; and cystic fibrosis had been excluded by a normal sweat test. At age 4 months he appeared his normal self when put to bed, but was found dead in bed the next morning.

\section{Necropsy findings}

The child died with acute cardiorespiratory failure with oedema of the lungs and obstructive tracheobronchitis.

There was some fibroelastosis in the heart and the trachea showed a considerable amount of squamous metaplasia and an apparent increase in the amount of elastic tissue deep to the basement membrane which itself appeared normal.

The length of the tracheal muscle was $6 \mathrm{~mm}$ which was above the 95 th centile.

Case 3 (aged 10 years). This child appeared to be perfectly well until aged 18 months when he was admitted to hospital with pneumonia from which he fully recovered. Subsequently he had frequent episodes of shortness of breath with wheezing which responded to bronchodilators. These episodes continued during the next 8 years in spite of bronchodilator and corticosteriod therapy and were, on occasions, associated with loss of consciousness, in which he would be pulseless and had to be given cardiac massage to recover. These unconscious attacks became a well recognised feature of his illness, but no explanation could be given for them despite extensive respiratory tract and cardiovascular investigations. His final fatal episode occurred while he was at school, where he had a severe attack of shortness of breath with wheezing. $\mathrm{He}$ rapidly became unconscious and failed to respond to resuscitation.

\section{Necropsy findings}

There was very slight clubbing of the fingers and toes; the chest was not barrel shaped. Lungs were voluminous and did not collapse on opening the chest, meeting in the midline over the heart. There was no interstitial emphysema. The brain showed pronounced oedema with flattening of the cortical convolutions and herniation of cerebellar tonsils into the foramen magnum. There was no CSF around the brain.

Histologically, the lung showed dilatation of alveoli in some areas and collapse in others, with some overgrowth of connective tissue and small semicrescents of fibroblasts which we term 'alveolar membranes'. The trachea and bronchi show basement membrane thickening with many subacute inflammatory cells beneath. The tracheal muscle measured $10 \mathrm{~mm}$ which, when corrected for crown to rump length, was considerably above the 100 th centile.

\section{Discussion}

When dealing with an aberration of growth, the question of cause and effect and function on structure becomes more and more complicated as more is learnt about the subject. This applies to the whole of the respiratory tract. In general, the more rapidly growing a tissue, the more susceptible it is to growth modification both in deformation and reformation.

In our series, the large number of children younger than 6 months (63 out of 74), suggests that these tracheal changes occur very early and points to the vulnerability of young children to respiratory disease. How long lasting and potentially harmful these changes are is difficult to assess.

Of the 74 cases analysed, 47 come into the category of cot deaths, an example of which is given in Case 2. Here, respiratory distress was present from birth with severe hacking cough. At necropsy, pulmonary oedema and obstructive tracheobronchitis were thought to be the cause of death, and the length of his membranous trachea was above the 95th centile. Respiratory tract disease plays an important role in children who die unexpectedly, but many of the histopathological changes found-for example necrosis of the vocal cord- ${ }^{4-7}$ can still not be evaluated.

Tracheal enlargement in children with respiratory diseases poses several questions: Is this a congenital or an acquired anomaly? What is its role in recurrent respiratory episodes? Can it be prevented? The evidence for this being a congenital anomaly is inconclusive. The early onset of symptoms in 17 children could be an indirect pointer towards this being a congenital anomaly. However, the possibility that the greatest tracheal deformity may be directly related to duration of symptoms indicates that an acquired element is in operation.

An analagous situation exists between distended lower airways - that is bronchiectasis-and disease of the respiratory system, particularly pertussis, pneumonia, and measles. ${ }^{8-12}$ The abnormalities described there occur in the muscular and elastic tissue of the bronchial wall. ${ }^{13}$ Our findings in the trachea are in keeping with stretching of all tracheal tissues, but more so in the membranous part where muscle and elastic tissues predominate, than in the cartilage.

Do these changes have any bearing on later disease? It is a common observation that, as 'chesty' children grow up, many lose their proneness to chest illness, but Colley ${ }^{14}$ showed that there is a link between childhood respiratory disease and recurrent chest problems in adults. Furthermore, the idea that the expanded trachea in childhood may be the beginning of greater tracheal distension in adults 
with recurrent respiratory tract disease is suggested by the reports of 'megatrachea'. Mounier-Kuhn ${ }^{15}$ first described this entity and there have been further reports from Jiménez Diáz ${ }^{16}$, Doyle et al., ${ }^{17}$ Rouan, ${ }^{18}$ Katz et al. ${ }^{19}$ Levowitz et al., ${ }^{20}$ Johnston and Green, ${ }^{21}$ and McKerron and Hewitt. ${ }^{22}$ Their suggestion that the disorder is of congenital origin is much more tenuous than is ours, since their youngest patient reported was just 7 years old.

Enlargement of airways has several deleterious effects on the efficiency of the respiratory system which could well predispose to a deterioration in respiratory function-for example, without a commensurate increase in lung capacity there is an increase in dead space volume which reduces the volume of air available for gas exchange; and unless ciliary action in conjunction with mucus secretion and circulation are improved, the clearing efficiency of the air purger is reduced. It is perhaps of some significance that in one of our cases (Case 2) there was some squamous metaplasia.

An important potential hazard to respiration lies in the lengthening in the posterior membrane. During expiration this membrane could conceivably move freely into the tracheal lumen causing a partial or total obstruction. While this state of affairs has been recognised in adults, ${ }^{23-25}$ it has not, as far as we are aware, been a feature of childhood respiratory embarrassment in conditions other than tracheooesophageal fistula, but the history of Case 3 could fit this concept.

This study has given us a hint that elongation of the posterior membrane, and the distended trachea, may have their beginnings in early childhood and may have a bearing on adult disease.

\section{References}

1 Wittenborg M H, Gyepes M T, Crocker D. Tracheal dynamics in infants with respiratory distress, stridor, and collapsing trachea. Radiology 1967; 88: 653-62.

${ }^{2}$ Dinstl K, Keminger K. Die Tracheomalacie als Zufallsbefund. Langenbecks Arch Chir 1970; 327: 925-7.

3 Baxter J D, Dunbar J S. Tracheomalacia. Ann Otol Rhinol Laryngol 1963; 72: 1013-23.

4 Cullity G J, Emery J L. Ulceration and necrosis of the vocal cords in hospital and unexpected child deaths. $J$ Pathol 1974; 115: 27-32.

5 Werne J, Garrow I. Sudden, apparently unexplained death during infancy. I. Pathological findings in infants found dead. Am J Pathol 1953; 29: 633-75.

- Werne J, Garrow I. Sudden, apparently unexplained death during infancy. II. Pathological findings in infants observed to die suddenly. Am J Pathol 1953; 29 : 817-31.

7 Adelson L, Kinney E R. Sudden and unexpected death in infancy and childhood. Pediatrics 1956; 17: 663-99.

8 Boyd G L. Bronchiectasis in children. Can Med Assoc J $1931 ; 25: 174-82$.

9 Marcy C H. Bronchiectasis. N Int Clin 1937; 1 : Series 47, 144-56.

10 Warner W P. Factors causing bronchiectasis: their clinical application to diagnosis and treatment. $J A M A$ 1935; 105: 1666-70.

11 Raia A. Bronchiectasis in children with special reference to prevention and early diagnosis. Am J Dis Child 1938; 56: 852-82.

12 Diamond S, Van Loon E L. Bronchiectasis. JAMA 1942; 118: 771-8.

13 Kline B S. The pathology of bronchiectasis and lung abscess. Am Rev Respir Dis 1931; 24: 626-35.

14 Colley J R T. The epidemiology of respiratory disease in childhood. In: Hull D, ed. Recent advances in paediatrics, No. 5. Edinburgh: Churchill Livingstone, 1976; 221-58.

15 Mounier-Kuhn M. Dilatation de la trachée constatations radiographiques et bronchoscopiques. Lyon Méd 1932; 150: 106-9.

16 Jiménez Diáz C. Un caso de megatraquea idiopatica con traqueomalacia. Rev Clin Esp 1940; 1 : 432-3.

17 Doyle J A, Rellan L M, Brea M M. Megatraquea y Bronquiestasias Congenitas (Sindrome de MounierKuhn). Rev Asoc Med Argentina 1954; 68: 579-80.

18 Rouan M. Un cas de trachéomégalie. J Fr Med Chir Thorac 1959; 13: 417-22.

19 Katz I, Levine M, Herman P. Tracheobronchiomegalythe Mounier-Kuhn syndrome. AJR 1962; 88: 1084-94.

20 Levowitz B S, Khalik G, Hughes R E, Conant J S, Weiss M. Tracheobronchiomegaly and chronic pulmonary disease. Dis Chest 1964; 46: 498-502.

21 Johnston R, Green R. Tracheobronchiomegaly. Am Rev Respir Dis 1965; 91 : 35-50.

22 McKerron C, Hewitt M. Tracheobronchiomegaly. Br J Dis Chest 1966; 60: 200-2.

23 Herzog H. Expiratory stenosis of the trachea and main stem bronchi due to a weakened pars membranacea. Ger Med 1960; 5: 73-7.

24 Liddelow $A$ G, Campbell A H. Widening of the membranous wall and flattening of the trachea and main bronchi. Br J Dis Chest 1964; 58: 56-60.

25 Campbell A H, Faulks L W. Expiratory air flow patterns in tracheobronchial collapse. Am Rev Respir Dis 1965; 92: 781-91.

Correspondence to Professor J L Emery, Children's Hospital, Congenital Anomalies Research Unit, Thornbury, Fulwood Road, Sheffield S10 3BR.

Received 17 April 1979 